\title{
Desentrañando la excepción: análisis doctrinario y comparativo sobre los estados de excepción constitucional
}

\section{Untangling the exception: A doctrinal and comparative analysis of states of exception}

\author{
Tomás de Rementeria Venegas ${ }^{1}$
}

"Todo Estado libre en el que no se hayan previsto las grandes crisis corre el riesgo de morir en cada tormenta" Jean-Jacques Rousseau

\section{RESUMEN}

El objeto de este documento es el examen jurídico comparativo en torno a la regulación normativa de los estados de excepción, acompañado de un análisis doctrinario e histórico de la institución. Ante una situación completamente anormal en todo el mundo, por la pandemia de Covid-19, se hace indispensable tener un análisis multidimensional de los regímenes excepcionales que ostentan las distintas naciones, así como también la búsqueda de su origen histórico y su contenido teórico, con el fin de conciliar los excesos y las debilidades de la institución, tomando una concepción republicana de la misma.

Palabras clave: estado de excepción, emergencia, derecho comparado, constitución

\begin{abstract}
This paper conducts a comparative legal examination of the regulation of states of emergency accompanied by a doctrinal and historical analysis of this institution. In the face of a completely abnormal situation throughout the World, due to the Covid-19 pandemic, it is essential to have a multidimensional analysis of the exceptional regimes held by different nations. Moreover, it is also necessary to enquire about their historical origins and theoretical contents so as to reconcile the excesses and weaknesses of the institution by taking a republican conception of it.
\end{abstract}

Keywords: state of exception, emergency, comparative law, constitution

Abogado, Master en Derecho Constitucional y Derechos Fundamentales Universidad Paris 1 Panthéon-Sorbonne, Doctorante Contractual Universidad Paris 1 Panthéon-Sorbonne, investigador del Institut des Sciences Juridique et Philosophique de la Sorbonne (ISJPS) 


\section{Introducción}

Resulta probable que nunca en la historia de la humanidad tantos países al unísono hayan declarado algún tipo de estado de excepción constitucional. El mundo entero ha sido puesto en jaque por este "enemigo" no convencional, el virus del nuevo coronavirus de Wuhan (Covd-SaRS-2). Este ha impuesto una situación excepcional, no solo sanitaria, sino que se extiende a aspectos como seguridad, economía, control fronterizo y educación. Para hacer frente a esta situación de anormalidad, los gobiernos han tenido que hacer uso de poderes excepcionales muchas veces reconocidos constitucionalmente.

En efecto, así como los seres vivos al ser afectados por un agente patógeno, poseemos mecanismos extraordinarios en nuestro cuerpo que permiten combatirlo, como el aumento de temperatura corporal que busca eliminar una bacteria, las lágrimas que buscan expulsar un elemento intruso de nuestro globo ocular o la inmunización producida por anticuerpos ante un virus. Los ordenamientos jurídicos deben procurarse de medios para combatir su propia destrucción o decadencia acaecida debido a circunstancias que escapan al curso normal de las cosas.

Hoy esas reglas han cobrado especial sentido, no solo por el reciente escenario pandémico, sino también por los efectos que se prevén para el cambio climático, las migraciones generadas por este, una eventual carestía de recursos naturales y alimenticios, o los escenarios extremos que pueden traer la robótica y/o la inteligencia artificial. Además de las que podríamos llamar "amenazas clásicas", como desastres naturales, ataques terroristas o la guerra convencional.

El objetivo de este trabajo es hacer un análisis comparativo y doctrinario con el fin de proponer un retorno a la idea clásica republicana del estado de excepción como mecanismo de salvaguarda de la propia existencia del Estado, en momentos de especial peligro para sus elementos constitutivos (población, territorio y Gobierno/administración). Para eso resulta necesario escapar de la concepción de estos como instrumento de control político, idealizada en los postulados de autores como Donoso y Schmitt. Así como también es preciso alejarse de la demonización sufrida, pero siempre haciéndose cargo de los posibles efectos perniciosos de estos. Para tales fines analizaremos los aportes doctrinarios y normativos que serán fundamentales para la elaboración y el reconocimiento de la necesidad de los estados excepcionales constitucionales y que a la vez los limite.

\section{La noción de "excepción constitucional”, contrastes lingüísticos}

Para el derecho comparado, la traducción semántica de los términos jurídicos resulta primordial, pues se trata de la interpretación de los conceptos de una lengua a otra. En efecto, la traducción implica al menos dos actos de interpretación. En primer lugar, de la interpretación del idioma original y seguidamente de la interpretación del idioma original a un idioma extranjero. De hecho, la traducción jurídica es efectivamente una cadena de interpretaciones judiciales, a través de importantes determinaciones lingüísticas. El término "estado de excepción" es uno de esos términos especialmente complejos de traducir, al ser una institución de distintos alcances y objetivos en las legislaciones internas de los estados, y adicionalmente un relato histórico diferenciado en cuanto a las palabras elegidas para el término.

En ordenamientos jurídicos de lengua española, el concepto está vastamente internalizado y se encuentra presente en las constituciones de países como Bolivia, Colombia, Chile, Espańa, Ecuador, Paraguay, República Dominicana y Venezuela. En otros países no se usa directamente el término, sino un vocabulario análogo. Por ejemplo, en la Constitución uruguaya se usa: "medidas de pronta seguridad", "suspensión 
de la seguridad individual" o "estado de guerra" (Esteva, 2002). Asimismo, la Constitución argentina no menciona el estado de excepción y se refiere a las instituciones de estado de sitio, intervención federal, decretos de necesidad y urgencia (DNU), y delegación legislativa (Hernández et al, 2003).

Por su parte, el término alemán para estado de excepción es Ausnahmezustand, que se traduce literalmente como estado de excepción (Ausnahme significa "excepción" y zustand, "estado de"), por lo que la aproximación a la institución en la cultura jurídica de habla alemana es equivalente a la que tenemos en la de habla hispana (Trotter, 1997). Sin perjuicio de que la mención no existe con ese nombre en las actuales constituciones alemana y austriaca.

Por otro lado, en el vocabulario jurídico francés la noción es relativamente desconocida; los franceses históricamente conocían el término état de siège (estado de sitio), relacionado con estados de guerra y no con una noción general de emergencias. Desde el antiguo régimen se consideraba la posibilidad de establecer un estatuto especial precisamente en los lugares sometidos a un sitio militar, otorgándole poderes a la autoridad local que se encontraba aislada de la metrópolis (Barthélémy, 1915). Después la doctrina degeneró el concepto y distinguió entre la figura del état de siege effectif(estado de sitio efectivo) y el état de siege fictif (estado de sitio ficticio) (Reinach, 2010). Este último no tenía por origen un sitio bélico, sino que todo peligro, ya sea interno o externo, también se le conoció como etat de siege politique (estado de sitio político) por el uso excesivo como instrumento de carácter político (Gal, 2017).

La cultura jurídica francesa hoy se refiere principalmente al estatuto de facultades excepcionales como état d'urgence (estado de emergencia) (MBongo, 2017). Pero el término "excepcional" es utilizado en la actual constitución de 1958 al referirse a los pouvoirs exceptionnels du président de la République (poderes excepcionales del presidente de la República). Similar es la situación en Italia, donde el término utilizado es principalmente Stato di Emergenza y, en caso de guerra, el Stato di Guerra, siendo este último el único con rango constitucional.

En las culturas jurídicas anglosajonas la situación es diferente, tanto en los Estados Unidos de Norteamérica (Ackerman, 2003) como en el Reino Unido de Gran Bretaña (Anderson y Adey, 2012). El término de uso común es el de emergency powers (poderes de emergencia) (Blick, 2014) y en menor medida state of emergency (estado de emergencia). También se resalta el concepto de la suspensión del habeas corpus con una amplia historia en derecho británico.

En la Constitución de la República Popular de China ocurre una situación particular con el término. A raíz de la enmienda constitucional de 2004 se sustituyeron todas las referencias a "ley marcial" (戒区法) con el concepto de “estado de emergencia" (戒区法). La introducción del concepto de estado de emergencia se basó en la idea de que podría utilizarse para indicar una situación de emergencia diferente a la guerra, lo cual se ha incorporado en otras constituciones nacionales y, por tanto, reforzaba la idea de China en la línea del mundo desarrollado y bajo la égida del Estado de Derecho (Chen, 2009).

De lo expuesto podemos generar una división taxonómica de las expresiones usadas:

- Expresiones centradas en la excepción: Siguiendo a la Real Academia de la Lengua, el vocablo "excepción” puede definirse como: "Cosa que se aparta de la regla o condición general de las demás de su especie" (DLE). Este tipo de acepciones a la institución tienen como base el régimen de anormalidad constitucional, excluyendo como elemento central el fenómeno que lo causa o las prerrogativas que otorga. Es el caso de la concepción ampliamente arraigada en la cultura jurídica de lengua espańola y la doctrina jurídica de idioma alemán. 
- Expresiones centradas en la causa de la situación excepcional: Otras expresiones utilizadas se centran en la situación de emergencia en sí, es decir, el origen de la situación excepcional. Es así como el estado de emergencia se refiere al hecho, la premura por resolver una contingencia. El estado de sitio tiene su origen en la situación de un sitio militar que aislaba una determinada parte del territorio y el estado de catástrofe se refiere a una situación de calamidad interna. Las expresiones en derecho francófono, italiano y chino se acomodan a esta categoría lexical.

- Expresiones centradas en los poderes otorgados: Por último, están las expresiones que se centran en los poderes que otorga la situación excepcional. En este caso, el elemento principal son las prerrogativas excepcionales que recibe el órgano estatal escogido para lidiar con la situación extraordinaria. El concepto anglosajón de poderes de emergencia (emergency powers) calza con esta categoría lexical.

De estas tres categorías llegamos a la conclusión que el núcleo central de las instituciones de excepción es el mismo y se constituye de tres elementos: una situación normativa excepcional, una causa, basada en un hecho fuera de lo común, con el cual no es posible lidiar con la normativa regular; y prerrogativas extraordinarias otorgadas a un órgano estatal. La diferencia es el énfasis otorgado por cada cultura jurídica a cada uno de los elementos, pero podemos reconocer una unidad en las instituciones.

\section{Concepción teórica y doctrinal del estado de excepción}

Históricamente, han existido normas que permiten a los Estados tolerar circunstancias excepcionales. Los romanos conocieron múltiples instituciones de emergencia como la dictadura, la declaración de hostis publicum, la Senatus consultum ultimum, los tumultos y el justitium (Willems, 2014), siendo la principal institución a tales eventos la dictadura. Efectivamente, la institución dictatorial no tenía la carga negativa que hoy posee; en palabras del profesor Maurice Duverger:

Para hacer frente a dificultades graves, se podía instaurar un Dictator: magistrado excepcional que escapaba a la regla de la colegialidad de funciones, cada una confiada normalmente a dos titulares cuyo acuerdo era necesario para tomar las decisiones. Por el contrario, el dictador decidía por sí solo, pero en un ámbito muy limitado y por un tiempo muy limitado (seis meses en general). Designado por los cónsules, a veces aprobado o propuesto por el senado, raramente elegido por el pueblo, era investido según los ritos consuetudinarios: al amanecer, en la ciudad misma. (Duverger, 1982, p. 7).

Por su parte, Maquiavelo en su Discurso sobre la primera década de Tito Livio, no escatimó loas a la efectividad de la dictadura en Roma como método de preservación de la República:

La dictadura era un cargo temporal: nombrábase dictador para resolver determinado conflicto y hasta que desapareciera; su poder alcanzaba a determinar por sí mismo los remedios al urgente peligro, a ponerlos en práctica sin necesidad de consulta, y a castigar sin apelación; pero no podía hacer cosa alguna que alterase las instituciones del Estado, como lo sería privar de su autoridad al Senado o al pueblo, o derogar la antigua constitución política para establecer otra nueva. De manera que por la brevedad del tiempo que la dictadura duraba, por la autoridad limitada que el dictador ejercía y por la pureza de costumbres del pueblo romano, era imposible cualquier extralimitación en daño de Roma. (Machiavelli, 2012, p. 115).

Tras un largo ocaso de la institución estatal (durante un medioevo marcado por la feudalidad), durante el renacimiento reapareció la idea de circunstancias excepcionales. La combinación de términos como la 
necesidad general y la razón de estado contribuyeron a la construcción del moderno concepto de estado de excepción. En efecto, el historiador italiano Scipione Ammirato (1599) entendió la razón de estado como una inobservancia a las razones ordinarias, por el respeto del bien público, siendo entendida como la base de la excepción que busca el mantenimiento del propio Estado y la preservación de sus elementos constitutivos.

Posteriormente, en el Contrato social, Jean-Jacques Rousseau enunció:

La inflexibilidad de las leyes, que no permita que se modifiquen según las circunstancias, puede hacerlas perjudiciales en ciertos casos, y causar de este modo la pérdida del Estado en una crisis. El orden y la lentitud de las formalidades exigen un espacio de tiempo que las circunstancias a veces no permiten. Pueden presentarse mil casos para los cuales nada ha determinado el legislador; y es necesario tener la previsión de que no es posible preverlo todo. No debe pues intentarse el afianzar las instituciones políticas hasta el punto de renunciar a la facultad de suspender su efecto. Hasta la misma Esparta dejó dormir sus leyes. (2009, p. 116.

De estas concepciones señaladas, desde la Roma antigua, pasando por la concepción republicana y finalizando en las doctrinas iluministas francesas, se le da expresión a una concepción republicana del estado de excepción. En efecto, la determinación de incluir normas que regulen situaciones extraordinarias no dice relación con la realización de una expresión política o un instrumento de dominación. Por el contrario, con un instrumento necesario para que tales situaciones fuera de lo común no desencadenen en la destrucción del Estado y por consiguiente la multiplicación de situaciones de dominación entre ciudadanos.

Si bien la mayoría de la literatura jurídica, al hablar de las raíces doctrinarias modernas del concepto de excepción constitucional, se remite a los escritos del jurista alemán Carl Schmitt, este tuvo su influencia fundamental en el jurista y filósofo español del siglo XIX Juan Donoso Cortés. Efectivamente, Donoso construyó su idea de la excepción en términos jurídicos, haciendo una analogía con el milagro en términos teológicos (Donoso, 1946). Este pensador conservador español acuñó su lema: "Derecho común para tiempos buenos, derecho excepcional para tiempos excepcionales" (Mayorga, 1993, p.288). La idea de un dictador a la imagen de un Dios que aparecía junto al milagro de la excepción completaba la construcción donosiana.

Pero, sin duda, quien exploró la teoría de la excepción de forma más refinada y con más influencia fue Schmitt. Este desarrolló la idea de la dictadura, recuperada de la terminología romana y de las teorías conservadoras de Donoso, distinguiendo entre una dictadura comisaria y una dictadura soberana. En la primera el dictador está liberado de las barreras legales, pero obligado a defender o restablecer la Constitución vigente. Por otro lado, en la dictadura soberana el dictador no está obligado por la Constitución suspendida, sino que busca establecer un nuevo orden político-constitucional (Schmitt, 2015). Es en su Teología política donde analiza de manera más minuciosa las implicaciones para la teoría del derecho del estado de excepción. En ese libro el jurista establece que es el soberano, el depositario de la auctoritas y por lo tanto quien decide el estado de excepción” (Schmitt,1988).

Schmitt desarrolló su teoría en torno a la excepción como expresión máxima de la soberanía y la decisión del soberano. Para el jurista teutón, la base era demostrar que el derecho no puede definir rigurosamente la esfera de acción del gobernante. Por el contrario, es el poder del gobernante el que crea las condiciones de aplicación del derecho; este no establece ningún criterio para distinguir una situación excepcional del caso normal. Por lo tanto, es responsabilidad del soberano decidir cuándo nos encontramos en el mundo 
de la excepción. No existiendo esta decisión, el derecho se mantiene indeterminado y carece de la eficacia necesaria para el cumplimiento de sus fines (Schmitt, 1988).

La importancia de la excepción en la construcción de la Teología política se evidencia en la siguiente cita:

La excepción es más interesante que el caso normal. Lo normal no demuestra nada, la excepción lo demuestra todo; no sólo confirma la regla sino que la regla sólo vive gracias a aquélla. En la excepción, la fuerza de la verdadera vida rompe la costra de un mecanismo cuajado en la repetición. Un teólogo protestante del siglo XIX lo expresó así: "La excepción explica lo general y a sí misma”. Y si lo general pretende estudiarse correctamente, sólo hay que buscar una verdadera excepción, la cual revela todo con mucha más claridad que lo general. A la larga se cansa uno de la palabrería eterna sobre lo general; existen las excepciones. Si no hay explicaciones para éstas, tampoco lo habrá para lo general. Por lo común no se repara en esta dificultad, porque lo general ni siquiera se concibe con pasión sino de una manera cómoda y superficial. La excepción, en cambio, concibe lo general con enérgica pasión. (Schmitt, 1988, p.29).

De esta forma, Schmitt invirtió la disposición generalmente aceptada, señalando que no es la excepción una consecuencia de la normalidad, sino que a la inversa.

Paradójicamente, la teoría de Schmitt tiene repercusión casi instantánea en un pensamiento que podría situar en las antípodas de los del jurista de Plettenberg. El crítico de arte y filósofo Walter Benjamin, en su octava tesis de la Filosofía de la Historia, señaló:

La tradición de los oprimidos nos enseña que el "estado de excepción" en que ahora vivimos es en verdad la regla. El concepto de historia al que lleguemos debe resultar coherente con ello. Promover el verdadero estado de excepción se nos presentará entonces como tarea nuestra, lo que mejorará nuestra posición en la lucha contra el fascismo. La oportunidad que éste tiene está, en parte no insignificante, en que sus adversarios lo enfrentan en nombre del progreso como norma histórica. El asombro ante el hecho de que las cosas que vivimos sean "aún" posibles en el siglo veinte no tiene nada de filosófico. No está al comienzo de ningún conocimiento, a no ser el de que la idea de la historia de la cual proviene ya no puede sostenerse. $(2008$, p. 43.)

Dicho esto, la posición de Benjamin debe entenderse como una rebelión contra la idea de Schmitt, una rebeldía contra el curso de la historia escrita por los vencedores. Los vencedores se convierten en los poderosos y en la doctrina schmittiana el poderoso es representado por el soberano, el depositario de la plenitio potestas, que tenía la prerrogativa de tomar la decisión sobre si estábamos dentro de la regla o dentro de la excepción.

Lo que denuncia la crítica de Benjamin contra esta violencia conservadora del poder (Benjamin y Subirats, 1998) es el efecto colonizador del derecho del soberano que se expande exponencialmente, haciéndose sentir en todos los aspectos de la vida, exhibiéndose como la única mediación posible para zanjar cualquier tipo de conflicto. Por ello, esta violencia legal, que afirma establecer una paz perpetua, no suprime la violencia natural, sino que la asimila y la utiliza a su propio beneficio en el ordenamiento jurídico.

Efectivamente, el concepto de excepción de Schmitt tiene un objetivo específico, el cual se encuentra en la construcción de un proyecto de hegemonía conservadora, tributario de la tradición del mencionado Donoso y otros autores como Hobbes, Burke y De Maistre. Este proyecto se construye en torno a la figura de autoridad providencial que, usando como herramienta la soberanía y la decisión sobre la excepción, refunda el poder político. Este proyecto tuvo su construcción magistral en la Ley Alemana de Plenos 
Poderes de 1933, con la cual Hitler asumió el control total de Alemania. Schmitt llanamente reconoció este acto como una nueva constitución (Grosser, 1984).

Recientemente, al estudio teórico del estado de excepción se ha sumado el filósofo italiano Giorgo Agamben, quien despliega una crítica al estado de excepción, que puede considerarse tributaria de la de Benjamin. Según él filosofo romano, lo fundamental en Benjamin es que relacionó un concepto de teología política, "tiempo mesiánico", con una categoría jurídica del derecho público: el estado de excepción. Según Agamben, este razonamiento de Benjamin permite especificar el reino mesiánico en los mismos términos que la teoría de la soberanía de Schmitt, al tiempo que establece paralelo entre la venida del Mesías y el fin del poder del Estado. Es decir que el tiempo mesiánico es ideado como un concepto definitorio que cuestiona toda la realidad. No obstante, el filósofo italiano empuja a límites exagerados la crítica de Benjamin, concibiéndola como un procedimiento capaz de realización del fin del Estado. Durante la venida del Mesías (la excepción), ante el fin de los tiempos (el katechon), sale a la luz el origen del derecho, a la vez que parte a las tinieblas el derecho mismo (Agamben, 2011).

Para Agamben, el estado de excepción es un mecanismo jurídico que separa el ethos —entendido como esencia de vida - del hombre, subyugándolo a vivir una vida vacía o desnuda, porque esta está sometida y depende de otro, de la arbitrariedad del poder decisorio del soberano (Salazar, 2018).

En el aporte de Agamben se distingue el concepto biopolítico de autoritas (autoridad) y el concepto jurídico de potestas, lo que es especialmente importante para analizar los estados de excepción. Agamben sostiene que en el estado de excepción (relacionado con las experiencias del fascismo en Italia y el nazismo en Alemania) no elevaba al poder excepcional a una magistratura (en este caso, jefe del Gobierno o canciller), sino que a una persona que en esta excepcional situación ha reunido en su augusta persona el carácter completo de la autoridad (la magistratura se indiferencia de la persona que temporalmente la ostenta) (Agamben, 2010). Estos raciocinios han llevado a Agamben a ser desconfiado de la idea de la excepción y ha preconizado en diversas oportunidades (post atentado a las torres gemelas, el combate del terrorismo en Francia y muy recientemente ante la pandemia del Coronavirus) la expansión excesiva del estado de excepción, amenazando no solo la democracia, sino que la vida humana misma.

En efecto, una concepción republicana de la excepción constitucional debe tener en cuenta los razonamientos críticos sobre la institución de Benjamin y Agamben, y a la vez revelar el proyecto soberanista y hegemónico de Schmitt. Especial importancia reviste — siguiendo la idea de Kantorowicz (1989) sobre las dos caras del rey: el gobernante como magistratura y el gobernante como persona- la distinción realizada por Agamben entre un estado de excepción personal y uno de magistratura. Lo óptimo es la existencia de un estado de excepción que siempre recae sobre una institución y no sobre la persona detentadora de esta en el momento de la emergencia.

Por su parte, en la doctrina jurídica hispanoamericana encontramos un desarrollo significativo sobre la excepción y la urgencia. Linares Quintana (1953) concibió la excepción como un método de subsistencia del Estado:

Ante circunstancias extraordinarias que perturben o amenacen el orden internacional y hasta la vida del Estado, como las que caracteriza a una conmoción interior o a una guerra, las autoridades deben hallarse investidas de los poderes adecuados para una eficiente defensa del orden constitucional, aun cuando ello se traduzca en un descaecimiento de las garantías de la libertad individual. Es una nueva aplicación del secular aforismo salus populis suprema lex est. (p. 395). 
Con esta frase, el destacado constitucionalista argentino registra que el Estado requiere de herramientas para defender su orden constitucional y, en definitiva, su propia existencia, en situaciones que escapan de la generalidad. La mención que hace del aforismo romano (salus populis suprema lex est) no es baladí, ya que este axioma puede traducirse como la salud —entendiéndola en un concepto mucho más amplio que el uso común, más cercana al concepto de bienestar actual— del pueblo debe ser la ley suprema (Cicerón, 1980).

En similares términos, el constitucionalista español Manuel García Pelayo exhibió que el derecho constitucional debe prever lo que podría ser una anormalidad jurídica, generando así una situación excepcional en que la normatividad normal se vuelve impotente para sobrellevar las especialísimas circunstancias en que se encuentra un Estado. Así aparece una situación dialéctica nueva, en la que, por la vía de la previsión, se introduce dentro de la normatividad constitucional la excepción como régimen consecuencial de la pérdida de la normalidad social y política:

El Estado de derecho es un estado absolutamente normativizado, un Estado cuya total actividad ha de desarrollarse en el marco de preceptos jurídicos previos de naturaleza general. Toda normatividad supone una normalidad, cuando esto no sucede estamos ante el caso excepcional, que requiere medidas excepcionales. Para que se trate de un caso excepcional se requiere que la situación tenga un carácter anormal y que sea limitada en el tiempo (...) El Estado de Derecho lleva en su propia dialéctica la necesidad de un derecho excepcional, es decir, de prever la excepción y de normativizar la misma excepción. (García, 1984, p. 153).

Asimismo, el destacado constitucionalista chileno Mario Verdugo Marinkovic, señalaba: "Pero el Estado, junto a su vida normal en el orden constitucional, tiene una vida anormal o patológica. Estado experimenta contratiempos, vive momentos difíciles y situaciones excepcionales" (Verdugo, 1980, p.30.) Las palabras del profesor Verdugo hoy poseen una especial significación (se podría reconocer su carácter casi adivinatorio) al establecer la "vida patológica del Estado". Efectivamente, siguiendo la analogía, los Estados sufren enfermedades fulminantes y la respuesta inmunitaria del ordenamiento constitucional es un estado de anormalidad constitucional que reconoce ciertas capacidades especiales a la autoridad estatal (Verdugo, 1980).

Por su parte, el jurista mexicano Diego Valadés nos entrega una importante advertencia sobre los regímenes de excepción en Latinoamérica. La historia de la utilización de los estados de emergencia y regímenes de excepción al sur del Río Grande ha sido especialmente errática y relacionada con la vasta tradición caudillista y autoritaria que ha azotado el continente desde los albores de las independencias del régimen colonial. A este efecto, Valadés indicó que

Es preciso considerar que los estados de excepción son mecanismos adecuados a la defensa del Estado, y que el Estado suele ser entendido en su acepción más restringida. Por otro lado, se sabe que los detentadores del poder suelen identificar su propio destino con el de las instituciones cuya titularidad ejercen, de manera que también aplican para su afirmación personal las defensas que fueron ideadas para las instituciones. (1974, p. 125).

Siguiendo la misma línea argumental, el profesor Héctor Fix-Zamudio (2004) señaló:

En todo planteamiento y análisis de los estados de excepción o de emergencia en nuestra región, es preciso distinguir entre la declaración y la aplicación de éstos por gobiernos constitucionales y democráticos de aquellos otros cuya declaración o aplicación son el prólogo o el instrumento para 
dar un golpe de estado, del que han surgido dictaduras o gobiernos de facto que actuaron al margen de los lineamientos constitucionales. No hacer esta distinción y dejarse llevar por la apariencia formal de juridicismo, y pensar que en algunas dictaduras o gobiernos de facto, cuando dejan teóricamente subsistentes algunas partes de la Constitución y sustituyen otras de manera arbitraria por medio de medidas legislativas expedidas por órganos incompetentes o ilegítimos, puedan existir garantías vigentes y derechos constitucionalmente protegidos, es una posición inadmisible, irreal y peligrosa. (p. 810).

Las observaciones de Fix-Zamudio y Valadés resultan importantes para entender los peligros de personalizar el estado de excepción (ya vistos en la crítica filosófica realizada por Agamben). Así pues, un estudio moderno de la institución debe ser cuidadoso en darle un estricto carácter institucional y reconocerlo como un instrumento de garantía de subsistencia del estado y no un vehículo para dar lugar o intensificar el gobierno personal.

En otro orden de cosas, el profesor español Francisco Fernández Cegado ha elaborado una fisonomía de los caracteres generales de la institución del estado de excepción. Reconoce a estos como: la concreción de circunstancias excepcionales reconocidas por la Constitución, la acumulación en el Gobierno de amplios poderes y la previsión normativo-constitucional de la necesidad de excepción. A la vez, Fernández reconoce una serie de requisitos del estado de excepción: la existencia de una grave amenaza contra el Estado, la imposibilidad de enfrentarse a esta amenaza a través de los medios jurídico-institucionales regulares, el cumplimiento de los requisitos formales reconocidos por cada texto constitucional y la temporalidad de la situación excepcional (Fernández, 1973).

Pasando a la doctrina jurídica francesa, debemos partir con la definición de la acepción Etat d'exception que nos entrega el profesor Bastien François en su diccionario de palabras claves del derecho constitucional. En este, rotula el término como:

Medida excepcional y temporal decidida en presencia de un peligro grave, por el cual un Estado, con el objetivo de asegurar su sobrevivencia o la de su población, suspende el derecho común en su funcionamiento y restringe libertades públicas, generalmente aumentando los poderes administrativos de los órganos policiales en detrimento de las autoridades judiciales, y algunas veces transfiriendo poderes hacia la autoridad militar. $(2017$, p. 22).

En el antiguo régimen, la prerrogativa real funcionó como la base del estado de excepción. Sin embargo, fue en la Francia postrevolucionaria que los teóricos y políticos le dieron su fisonomía. Así, el marqués Nicolas de Condorcet señaló: "una ley inapelable que impida actuar, cuando la acción es evidentemente necesaria, y que no dejaría a la voluntad nacional ninguna forma de manifestarse cuando la salvación pública exige que se pronuncie; una tal ley sería un absurdo y una verdadera tiranía" (France, p. 172175). Es interesante notar que Condorcet reconoció el carácter a la vez tiránico y absurdo al que se puede llegar con el excesivo celo en la observancia de los formalismos legales. Resulta evidente que la inexistencia de un criterio que permita al Estado actuar de formas extralegales en momentos extraordinarios resultaría en un grave peligro para el Estado y sus ciudadanos. La máxima revolucionaria fue que, si las circunstancias lo exigirán, en nombre de la integridad de la República, la necesidad se convertía en la ley (Saint-Bonnet, 2001).

Por su parte, el destacado jurista y decano tolosano Maurice Hauriou, señaló "una contradicción entre la ley y las condiciones necesarias para la existencia del Estado, que se podría decir que son más fundamentales que las reglas positivas de la constitución escrita” (Hauriou, 1909, p. 194). Asimismo, el constitucionalista estrasburgués Raymond Carre de Malberg indicó que 
cuando circunstancias de fuerza mayor ponen al Estado en la imposibilidad de conformarse con las normas del orden constitucional en vigor, para efectuar las modificaciones que las circunstancias mismas vuelvan imprescindibles, los intereses superiores del Estado no pueden ser sacrificados por cuestiones de forma; es así sobre todo cuando el Estado se haya amenazado incluso en su conservación como tal. De la necesidad misma, nace para el Estado un derecho a tomar todas las medidas de seguridad necesarias por estos acontecimientos. (2004, p. 613).

Dicho esto, el profesor Carré de Malberg reconoció en el estado de excepción una inconstitucionalidad que se justifica por su fundamento político y práctico. La posición de estos dos insignes constitucionalistas galos se explica en el contexto de la Tercera República, por lo que no es de extrańar que la situación caótica de un país sin una constitución codificada y un régimen político que cambiaba vertiginosamente según las circunstancias llevara a necesitar regímenes excepcionales e interpretaciones extensivas.

La jurisprudencia administrativa ha colaborado a darle fisonomía a la excepción en derecho francés. Por intermedio del llamado Arrét Heyries del Consejo de Estado, vio la luz el principio administrativo llamado de circunstancias excepcionales. Este permite al juez administrativo ser menos riguroso en el análisis de la legalidad de las actuaciones del Estado siempre y cuando por la existencia de una situación totalmente fuera de la normalidad (guerra, cataclismo, agitación social, entre otras), se imposibilite total o parcialmente la capacidad del Estado de actuar conforme a la legalidad vigente (Massot, 2013).

Debemos mencionar, eso sí, que durante mucho tiempo el término "régimen de excepción" en Francia trajo consigo una carga negativa, conectada con la legislación de excepción del régimen de Vichy ${ }^{2}$. Por lo tanto, como un término con carácter despectivo y enlazado con la idea de un derecho represivo, ilegítimo e inmoral, ya que las medidas excepcionales de Petain fueron la creación del infausto estatuto de los judíos, la fijación de tribunales excepcionales, encarcelaciones masivas, pérdidas de nacionalidad por motivos políticos y persecución de funcionarios públicos (Attali, 2008). En este punto es posible divisar un paralelo con la institución señalada por Valadés y Fix-Zamudio, a razón del uso personalista y autoritario de esta. Acá divisamos el hecho de que el derecho y la terminología jurídica no pueden ser aislados de las circunstancias históricas de su uso o creación.

Últimamente, la literatura especializada ha vuelto a tornar sus ojos a los estados de excepción, especialmente luego de los atentados terroristas de París de noviembre de 2015. El académico marsellés Bernard Manin (2008) entrega los elementos constitutivos del estado de excepción:

1) La autorización para relegar las normas superiores, como las que a menudo están contenidas en la Constitución.

2) Sometimiento a condiciones especiales para garantizar que las circunstancias requieren el número (1).

3) Limitación temporal de (1).

A la luz de las condiciones de Manin, similares a las reconocidas por el profesor Fernández Cegado en el caso español, algunos constitucionalistas franceses han sido cautelosos ante la difícil delimitación temporal de los estados de excepción ante conflictos que escapan a la tradicional guerra entre naciones o

El locus classicus en la materia es Duverger, Maurice (1983): "La perversion du droit", en Religion, société et politique: mélanges en hommage à Jacques Ellul (Paris, P.U.F), pp. 705-718 
a cataclismos naturales bien delimitados en el tiempo, atemporales como la amenaza terrorista siempre latente. Los destacados publicistas franceses Olivier Beaud y Cecile Guerin-Bargues han denunciado que

Lo más preocupante es que el actual Gobierno se propone luchar contra el terrorismo mediante el estado de emergencia. A nuestro juicio, es inaceptable porque hay aquí una contradicción manifiesta: el estado de excepción se piensa para reaccionar a una amenaza temporal, circunstancial. Su estructura está condicionada por la idea que la amenaza que le da a luz es en sí misma temporal. (Beaud y GuerinBargues, 2018, pp. 162-163).

En la opinión de Brian Loveman, con la British Riot Act de 1714 se inició la historia moderna del estado de excepción como hoy lo conocemos. Esta fue adoptada por los reyes de la casa de Hannover, para contener los tumultos provocados por los partidarios de los Stuardo. Esta norma autorizó a las fuerzas del orden a utilizar sus armas para dispersar, tras las advertencias de uso, los grupos de más de doce personas susceptibles de declinar en una rebelión. Concedió un privilegio jurisdiccional tanto a los soldados como a los simples ciudadanos que hubiesen herido a los manifestantes que se negaran a dispersarse o que hubieran provocado la muerte de estos últimos, en la medida en que tales hechos no pudieran implicar su responsabilidad penal (Loveman, 1993).

En la doctrina jurídica británica hay un amplio desarrollo del concepto de estado de excepción, contenida en la idea de la suspensión de la doctrina del habeas corpus. Es así como el célebre jurista sir William Blackstone (1979) exploró la existencia de una excepción reconocida constitucionalmente en la figura de la suspensión del habeas corpus, señalando:

Sin embargo, a veces, cuando el Estado está en grave peligro, tal medida puede ser necesaria. Pero la virtud de nuestra Constitución es que no autoriza al poder ejecutivo a determinar si el peligro para el Estado es tal, que pueda justificar esta medida. Corresponde exclusivamente al Parlamento, o poder legislativo, cuando lo considere apropiado, autorizar a la Corona, suspendiendo el Habeas corpus por un período breve y limitado, a encarcelar a personas sospechosas sin dar razón alguna. Así como el Senado de Roma estaba autorizado a recurrir a un dictador, un magistrado con autoridad absoluta, cuando estimaba que la República corría un peligro inminente (...) De la misma manera, esta práctica sólo puede ser utilizada en caso de extrema urgencia; y haciendo esto la nación renuncia un tiempo a su libertad, para conservarla para siempre. (p. 132).

Más de un siglo después, otro destacado jurista británico, Albert Dicey, resaltó la necesidad de temporalidad de esta excepción, preocupándose de qué pasaba una vez terminado el régimen de excepción. Ciertamente, en caso de que los responsables públicos no cumplieran las restricciones legales, no era posible hacer nada en su contra, ya que se había suspendido el habeas corpus y era probable que todas las detenciones estuvieran justificadas por acusaciones o sospechas de traición. Pero tan pronto como se restableciera el amparo a la libertad ambulatoria, las autoridades que habían cometido abusos injustificados durante su suspensión debían responder ante la justicia, tanto civil como administrativamente. Dicey (1982) indicó que

La ley de suspensión no confiere ninguna impunidad civil o penal a una persona que haya violado la ley. Los funcionarios públicos, pueden haber detenido a una persona de buena fe, considerando que esta acción estaba justificada por las exigencias del mantenimiento del orden. Pero esto no basta, ya sea que el Habeas corpus esté suspendido o no, para exonerar a los que han procedido a esas detenciones de sus responsabilidades por los daños que han infligido a esas personas. (p. 402). 
Dicey no consideró, como sí lo hizo Blackstone, que la pérdida de libertades era justificada por su brevedad temporal. El mérito de la limitación temporal es que permitía ex post analizar y cuestionar las acciones de la autoridad durante la excepción. Justamente, al final de la interrupción del derecho común era posible obligar a rendir cuentas a las autoridades estatales por lo que habían hecho durante la suspensión.

El jurista Dicey también hizo un análisis de otra institución de carácter excepcional, la ley marcial, distinguiendo dos sentidos en la expresión. Si la ley marcial representa el derecho a repeler la fuerza por la fuerza en caso de invasión, de sublevación, de revueltas o, en términos más generales, de toda resistencia violenta a la ley, entonces forma parte del derecho británico y puede concebirse dentro del concepto de Estado de derecho. No obstante, si la expresión designa la suspensión temporal de las leyes ordinarias, el reemplazo de tribunales civiles por tribunales militares y la supresión de poderes distintos al ejecutivo, esto es ajeno tanto al régimen jurídico británico como a las normas básicas de un Estado de derecho (Dicey, 1982). Lo interesante en este caso es que Dicey vuelve a destacar la temporalidad, dejando abierta la puerta al estudio de las circunstancias que permitieron poner en obra la ley marcial: "Se debe tener siempre presente que la cuestión de si la fuerza empleada es necesaria o excesiva, especialmente cuando haya causado la muerte, lo cual en última instancia corresponderá a un juez y un jurado" (Dicey, 1982, p.404).

Lo señalado por Dicey pudo verificarse fácticamente cruzando el Atlántico, en los Estados Unidos, durante la guerra de la secesión. Efectivamente, el presidente Lincoln en 1862 puso en marcha la ley marcial en todo el territorio estadounidense, suspendiendo el derecho a habeas corpus e imponiendo tribunales militares. Lincoln pensaba que los tribunales civiles tenían la facultad para juzgar a individuos y grupos pequeños bajo cargos de crímenes comunes. Pero las circunstancias de guerra y de crímenes de traición (los cuales muchas veces no eran sancionados en las legislaciones estatales) escapaban de esa competencia y de serlo afectarían el esfuerzo bélico contra los confederados (Furlong et al, 1987). En 1866, tras el fin de la guerra, la Corte Suprema de los Estados Unidos, en su célebre sentencia Ex Parte Milligan, dictaminó que los tribunales militares fuera del teatro de operaciones militares eran inconstitucionales. La Corte señaló minuciosamente los requisitos del uso constitucional de la ley marcial. Esta no podía ser el resultado de una amenaza de invasión. La necesidad debía ser real y presente; la posible penetración enemiga debía ser demostrada, llevando esa inminencia al cierre de los tribunales e impidiendo la acción de la administración civil (Supreme Court of the United States, 1866)

En los últimos años, la academia jurídica norteamericana ha sido especialmente crítica de la extensión que han tomado los poderes excepcionales del ejecutivo desde los atentados terroristas del 11 de septiembre de 2001. A modo meramente ejemplar, el destacado profesor de la Universidad de Toronto, David Dyzenhaus, ha seńalado que George W. Bush luego de recibir una serie de poderes excepcionales a través de las resoluciones del congreso post 9-11, consideró que tenía carta blanca (Dyzenhaus, 2009).

\section{Normativa comparada}

Ahora, con fines de solventar una nueva mirada optimista sobre los estados de excepción, analizaremos cómo los países tratan la institución de la excepción en sus órdenes constitucionales.

En el caso de Alemania, la normativa sobre los estados de emergencia fue elaborada en 1968, en momentos que la Facción del Ejército Rojo había realizado múltiples atentados terroristas y se vislumbraba un tema de grave agitación social ad portas de los Juegos Olímpicos de Múnich de 1972. Recordemos que los alemanes en la elaboración de su norma constitucional no habían incluido normativa sobre el punto, 
debido al recuerdo del mal uso del artículo 48 (plenos poderes) de la Constitución de Weimar que había realizado el régimen nazi. La Ley Fundamental de Alemania instituye los estados de excepción desde una mirada garantista que otorga un rol primordial al Parlamento en su uso y aplicación. Se consideran cuatro regímenes de excepción: el estado de defensa (artículo 115) o de emergencia externa, que acece cuando el territorio federal es objeto de una agresión militar o la inminencia de esta; el estado de tensión, el paso previo a la declaración de un estado de defensa (artículo 80), el caso en que se produce una catástrofe (artículo 35), la ocurrencia de un cataclismo natural o un siniestro de gran gravedad y, aunque no exista una definición constitucional expresa, el estado de emergencia interno que contiene, a su vez, el estado de catástrofe regional o suprarregional y el estado de emergencia en sentido estricto, cuando concurra un peligro apremiante para el orden fundamental, liberal y democrático (Faggiani, 2012).

Por su parte, Francia vislumbra en el artículo 16 de la Constitución de 1958, el ejercicio de los poderes de excepción por parte del presidente de la República. En palabras de los juristas Philippe Ardant y Bertrand Mathieu, se instituye una especie de "dictadura de salvación pública". De Gaulle decidió introducir esta institución en su carta fundamental por su experiencia, ante la impotencia de los poderes públicos para afrontar la invasión alemana en 1940. Las condiciones copulativas para la aplicación de este articulo son: una amenaza grave o inmediata que hace peligrar la integridad del territorio francés, las instituciones de la República, la independencia de la nación y la ejecución por parte de Francia de sus compromisos internacionales; y la interrupción del funcionamiento regular de los poderes públicos.

Si bien el presidente de la República puede acudir al artículo 16 libremente, debe consultar obligatoriamente a los jefes de las asambleas legislativas, al primer ministro y al Consejo Constitucional. Adicionalmente, el Parlamento continúa funcionando durante la situación excepcional (sin poder ser disuelto), pudiendo convocar a la destitución del presidente o censurar al Gobierno. Por otro lado, el presidente debe consultar al Consejo Constitucional sobre sus acciones y este debe pronunciarse en caso de buscar extenderlo por más de treinta días. Por último, el juez administrativo está habilitado para revisar todas las actuaciones del orden administrativo realizadas por el presidente y las actuaciones de índole legislativa son susceptibles de un control de constitucionalidad al fin de la aplicación de este régimen excepcional (Ardant y Mathieu, 2018). Adicionalmente, en el artículo 36 se encuentra el estado de sitio y en la Ley 55/385, del 3 de abril de 1955, se establece el estado de emergencia. Estos refuerzan el poder de las autoridades, sean civiles o militares, en hipótesis de peligro interno o externo, y solo pueden ser aplicados doce días antes de ser aprobadas por el Parlamento (Ardant y Mathieu, 2018).

En el caso de España, el artículo 16 de la Constitución (título XVI que regula las relaciones de las cortes con el Gobierno) establece los estados de alarma, de excepción y de sitio. Dicho marco constitucional viene a ser completado por la Ley Orgánica 4/1981. El carácter garantista del régimen español es innegable; se instaura la injerencia de las cortes, ya sea a través de la participación en la declaración o la autorización de esta o su extensión, dependiendo del estado excepcional decretado. Asimismo se establece la indisolubilidad de la Cámara durante la vigencia del estado de excepción. Se anuncia igualmente la convocatoria automática de las Cámaras, si estas no se encontraran reunidas, la no interrupción del funcionamiento de las mismas ni de los demás poderes del Estado y, adicionalmente, la responsabilidad de los poderes públicos y de sus agentes (Aba, 2011).

Por su parte, Portugal (artículos 19 y 138) y Malta (artículo 47) reconocen en sus Cartas Fundamentales el estado de emergencia y el estado de sitio, en ambos casos con un estricto control parlamentario y limitaciones temporales precisas. Medidas de excepción más genéricas se contemplan también en las Constituciones de Grecia (artículo 48, declaración de emergencia) y Chipre (artículo 183, proclamación 
de emergencia), en ambos casos nuevamente sometidos a control parlamentario y plazos temporales establecidos.

Siguiendo en Europa Central, en el orden constitucional de Hungría se encuentran muy extendidos los estados de excepción, llamados “órdenes legales especiales" en los artículos 48 a 54 de la Ley Fundamental húngara. Existen cinco suposiciones: el estado de extremo peligro (artículo 53), el estado de emergencia (artículo 50), en caso de un desastre natural o un accidente industrial que amenazan la vida humana y los bienes de las personas; el estado de crisis nacional (artículo 49), la defensa preventiva (artículo 51) y el estado de guerra (artículos 48 y 52). Todos poseen distintos titulares y distintos roles del Parlamento en su autorización y extensión.

En la misma región, Polonia (capítulo XI de la Constitución de 1997) prevé el evento de implantar, en situaciones de específico peligro, en caso de que la legislación común no resulte adecuada, las medidas de excepción de la ley marcial (artículo 229), el estado de emergencia (artículo 230) o estado de desastre natural (artículo 232). Lo interesante de la normativa polaca es que fija seis principios para la aplicación de estados de excepción, a saber: excepcionalidad, legalidad, proporcionalidad, limitación de los motivos, estabilidad normativa y protección de la representación política (Minerva Center, 2016a). Es interesante notar que la fijación de estos principios y lo cuidadoso que ha sido el constituyente polaco en regular los regímenes de excepción debe tener su origen en la traumática aplicación de la ley marcial durante los años 1981 y 1982, a través de la cual el régimen prosoviético persiguió al movimiento Solidaridad.

Por su parte, Eslovaquia instituye el estado de guerra en el caso de ataque externo o por encontrarse ligado por tratados internacionales de defensa común contra la agresión (artículo 102.1 letra 1), el estado de excepción y el estado de emergencia. Su vecino, la República Checa, establece en su Carta Fundamental el estado de guerra y de catástrofe natural, industrial o ecológica (ambos en el artículo 43) (Faggiani, 2012).

En Europa del Este, Rumania en su normativa tiene las hipótesis de movilización de las fuerzas armadas (artículo 92). El estado de guerra, de sitio y de emergencia se encuentran contenidos dentro de lo que denominan medidas de emergencia del artículo 93. La República de Bulgaria vislumbra el estado de guerra, la ley marcial y los estados de emergencia que pongan en riesgo el sistema constitucional (artículos 57 y 64). La Constitución lituana, por su parte, reconoce la ley marcial, en el supuesto de un ataque armado o el caso de operaciones militares y el estado de emergencia, en el caso de amenaza interna a la paz o al régimen constitucional (artículo 144). Las Constituciones de Eslovenia (artículos 16 y 92 C), Estonia (artículos 78, 87, 129 y 130) y Letonia (artículo 62) reconocen el estado de guerra y el estado de emergencia (Faggiani, 2012).

Por último, países como Italia, Austria, Bélgica, Luxemburgo, Holanda, Dinamarca, Suecia e Irlanda no recogen expresamente en sus Constituciones los estados de emergencia, excepción del estado de guerra externa.

Saliendo de la UE, pero aún en Europa, en Suiza la Constitución federal distingue tres regímenes. Uno es el régimen de plenos poderes. En este, el Consejo Federal está implícitamente facultado por la Constitución para adoptar todas las medidas necesarias, incluso si son inconstitucionales, para proteger la seguridad, la independencia y la neutralidad del país, en caso de que la Asamblea Federal no pueda reunirse. Esta tiene la posibilidad de confirmar este estado cuando pueda reunirse nuevamente, pero en caso contrario puede invalidar las actuaciones del consejo. Este instrumento fue utilizado durante las dos guerras mundiales. 
El segundo régimen es denominado "régimen de estricta necesidad" y rige cuando el Parlamento no puede funcionar y por lo tanto el Consejo Federal asume el poder de legislar mediante decretos de necesidad, incluso derogando la Constitución. Nunca ha sido utilizado. El último régimen es el artículo 102 de la Constitución, que confiere al Consejo Federal el deber de la seguridad exterior del país, manteniendo su independencia y neutralidad. Desde 1914, el Gobierno suizo ha invocado este artículo en momentos de peligro inmediato, en materias no reguladas por las leyes. Así, en cierto sentido, el Consejo Federal funciona como un legislativo. Sin embargo, tales ordenanzas no pueden contener disposiciones contra la Constitución, leyes y resoluciones de la Asamblea Federal (Baudoui et al, 2016).

En el caso de Reino Unido, los estados de emergencia se encuentran regulados por la martial law (ya mencionada más arriba en el análisis realizado por A.V. Dicey), la Bill of indemnity y principalmente por la Civil Contigencies Act de 2004. Esta última confiere la facultad de dictar reglamentos de emergencia a la reina, quien los dicta mediante una Order in Council. En el ejercicio de este poder, la reina debe actuar de conformidad con la recomendación de los ministros, en particular las recomendaciones del ministro del Interior. Regula la manera en que la reina podrá delegar esa autoridad a un ministro de la corona, ante condiciones de extrema urgencia, siempre en el espíritu de que los reglamentos representan una excepción que solo debe ser usada cuando sea impracticable la aplicación de la legalidad regular (Office Cabinet, 2020). Debe mencionarse que Gran Bretaña no posee una constitución codificada, pero históricamente las leyes relativas a emergencias se han considerado de rango constitucional (Cotter, 1953).

En Turquía, la Constitución, en su artículo 119, prevé la declaración de estado de emergencia en cuatro casos: desastres naturales, enfermedades epidémicas peligrosas, crisis económicas graves y actos generalizados de violencia con grave deterioro del orden público. La Constitución también permite la declaración de la ley marcial y estado de guerra. Además de la Constitución, existe la Ley sobre el estado de emergencia de 1983, que regula todas las potestades, procedimientos, derechos y responsabilidades que se aplican a los diversos regímenes excepcionales.

Pasando al continente asiático, en la Constitución de la India, en su parte XVIII, se reconocen las llamadas "provisiones de emergencia" en caso de guerra externa o rebelión interna (artículo 352). Antiguamente el artículo hablaba de "disturbios internos", vocablo que fue reemplazado por la $44^{\mathrm{a}}$ enmienda (hubo un largo proceso de mal uso durante el gobierno de Indira Gandhi), pero se mantiene entre las situaciones protegidas por el Estado ante una emergencia en el artículo 355, que sirve como paraguas jurídico de toda emergencia interna (Legal, 2020). Asimismo, el artículo 356 permite al presidente tomar ciertas funciones de los gobiernos estatales en caso de grave crisis. El estado de emergencia es declarado por el jefe de Estado, pero está sujeto a la sugerencia por escrito del Gabinete Gubernamental y a la aprobación de ambas las Cámaras del Parlamento con una mayoría calificada dentro del mes siguiente de su declaración. En caso de no ser revocado con anterioridad, la duración del régimen excepcional es de seis meses, pero puede ser renovado con el mismo procedimiento, con un plazo máximo de tres años.

En el caso de Japón, su Constitución menciona en el artículo 54 el término "emergencia nacional”, pero no existe ninguna provisión constitucional sobre la materia, dejando todo el asunto de la excepción y emergencias bajo la tutela de la Ley de medidas contra desastres de 1961. Esta deja la facultad de establecer un estado de emergencia al primer ministro, debiendo aprobarlo la Dieta en los primeros veinte días (existe una situación especial ante el caso de una emergencia nuclear donde no se requiere autorización de la Dieta) (Fenwick, 2009).

En el caso de la República Popular China, primero debemos considerar que la situación de China es especial. Como bien lo describe Jacques Delisle (2009), es un país donde podríamos decir que hay 
un estado de emergencia permanente jamás declarado. La Constitución china reconoce el derecho del presidente a declarar el estado de emergencia (jinji zhuangtai es la transcripción pinyin) con acuerdo de la Asamblea Popular (artículos 67 y 80) y regulado por la Ley de Respuesta a Emergencias. Las emergencias incluyen desastres naturales, accidentes calamitosos, incidencias de salud pública y acontecimientos de seguridad pública que ocurren abruptamente y causan o pueden causar un daño social grave y para los que es necesario adoptar medidas para hacerles frente.

Pasando al continente americano, la Constitución de los Estados Unidos incluye solo tres menciones relativas a las emergencias. La primera aparece en el artículo 1, sección 9, que se refiere a la suspensión del habeas corpus en casos de rebelión o invasión. El artículo 1, sección 8, establece que el Congreso tiene derecho a declarar la guerra. La tercera mención surge en la Quinta Enmienda, que establece las limitaciones a los juicios de grandes jurados en tiempos de guerra. Tampoco existe un régimen único en términos legales. A nivel federal, la legislación autoriza al presidente, en ciertas circunstancias restringidas y claramente definidas, a aprobar el uso de tropas federales para controlar la violencia doméstica, reprimir las insurrecciones y hacer cumplir ley federal. Estas leyes, sin embargo, no autorizan al Ejecutivo a suspender o interferir con el funcionamiento normal de las otras ramas del Gobierno o para limitar derechos fundamentales, con la sola excepción del derecho de habeas corpus, que el Congreso podrá suspender temporalmente cuando así lo requiera la seguridad pública.

A nivel estatal y local existen diversas disposiciones de emergencia que permiten al Ejecutivo del Estado (gobernadores o alcaldes, según el nivel) tomar medidas de emergencia. Estas disposiciones se basan en el poder general de la policía que poseen los Estados de acuerdo con la Constitución. Si no es irrazonable o arbitrario, un Estado está autorizado para infringir lo que de otro modo podría considerarse protegido por la Constitución, con el fin de garantizar la protección del bienestar, la seguridad y la salud pública de los ciudadanos (Minerva Center, 2016b).

A su turno, la Constitución de Brasil, en el artículo 136 reconoce el estado de defensa, el que puede ser declarado por el presidente de la República, debiendo oír al Consejo de la República y al Consejo de Defensa Nacional para preservar o restablecer en breve tiempo, en lugares concretos y determinados, el orden público o la paz social amenazadas por una grave y eminente inestabilidad institucional, o afectadas por calamidades naturales de grandes proporciones. El Congreso Nacional deberá examinar el decreto que declara el estado de defensa, en un plazo de diez días. Por su parte, el artículo 137 reconoce el estado de sitio, que presenta dos hipótesis: conmoción grave de repercusión nacional o sucesión de hechos que demuestren la ineficacia de la medida tomada durante el estado de defensa; y declaración de estado de guerra o respuesta a una agresión armada extranjera. En el primer caso no podrá extenderse por más de treinta días, los cuales pueden ser prorrogables siempre por el mismo término; en el segundo caso, el estado de sitio se mantiene en el transcurso de las hostilidades.

En el caso chileno, la Constitución de 1980 reconoce como estados de excepción el estado de asamblea (artículo 43, el cual responde a una situación de guerra externa), estado de sitio (artículo 40, guerra externa o conmoción interior), estado de emergencia (artículo 42, grave alteración del orden público o daño o peligro para la seguridad de la nación) y estado de catástrofe (artículo 41, calamidad pública). Estos se encuentran regulados orgánicamente por la Ley Orgánica Constitucional (18.415) de Estados de Excepción. Cada uno regula de distinta manera los derechos a ser limitados, su duración y las autorizaciones necesarias (Decreto 100, 2005).

La Constitución de los Estados Unidos Mexicanos en su artículo 29 fija un estado de excepción genérico aplicable para los casos de invasión, perturbación grave de la paz pública o de cualquier otro que ponga 
a la sociedad en grave peligro o conflicto. Le otorga la prerrogativa al presidente, con la aprobación del Congreso. Estima que el Congreso, en caso de no encontrarse sesionando, debe reunirse de pleno derecho, y como elemento interesante reconoce expresamente el elemento de proporcionalidad entre la afectación de derechos y el peligro eventual o presente el cual se quiere combatir.

\section{Conclusiones}

Con este estudio comparativo, tanto semántico como doctrinario y normativo, se ha buscado recuperar una concepción republicana del estado de excepción, tributaria de la dictadura romana, la doctrina de la razón de Estado y el aporte de la filosofía moderna. Resulta indispensable, eso sí, ser conscientes de los riesgos inherentes de los poderes excepcionales. En medio de la crisis del coronavirus hemos visto cómo estos han sustentado decisiones totalmente desmedidas e injustificadas en Hungría, Filipinas o El Salvador. Por otro lado, es evidente que el celo excesivo en el respeto de la rigidez de la norma jurídica ha sido un obstáculo importante para que los Estados puedan reaccionar ante una crisis extraordinaria.

El rescate del estado de excepción como institución de salvaguarda de la continuidad estatal no es algo baladí. El Estado tiene una obligación de cuidado sobre su población, territorio y Gobierno, que a la vez constituyen su propia existencia. Sin embargo, la búsqueda de ese objetivo no puede ser un cheque en blanco para la realización de acciones aberrantes o la utilización de poderes extraordinarios de modo injustificado. Aparece el rol primordial que debe dársele a los jueces y a los Parlamentos en el control de la existencia misma de las circunstancias que originaron el régimen de excepción, como también el respeto del núcleo de derechos básicos que debe mantenerse. En efecto, no resulta razonable considerar que en nombre de una continuidad del Estado se restrinjan derechos como el derecho a la vida o a la integridad física, pero parece comprensible aceptar la restricción de libertades como la de desplazamiento o el derecho de propiedad.

Sobre el control judicial, resulta razonable en el escenario actual que los jueces ganen un protagonismo importante como guardianes de los derechos y libertades de las personas ante ejecutivos con alto poder, dadas las circunstancias excepcionales. El poder de control de parte del poder judicial debe mantenerse antes, durante y después del régimen excepcional, pudiendo juzgar las circunstancias originarias del régimen de excepción como actuaciones mismas de las autoridades durante este. Lo mismo se aplica a los Parlamentos que deben tener injerencia en la declaración del estado de excepción, así como también mantenerse sesionando (ya sea por medios presenciales o, en circunstancias realmente excepcionales como las actuales, por medios telemáticos) y cumpliendo sus funciones fiscalizadoras. Sería también recomendable el establecimiento de comisiones de control cada vez que se dicte un nuevo régimen excepcional.

Por último, los Parlamentos deben poseer instrumentos para calificar las circunstancias originarias y el alcance del estado de excepción, pudiendo hacer efectivas responsabilidades sobre los ejecutivos. En regímenes parlamentarios es mucho más sencillo por el mecanismo de censura, pero en regímenes presidenciales deben poder verificarse las causales de destitución presidencial establecidas en cada ordenamiento jurídico. Lo anterior, comprendiendo que la idea de Schmitt de un acto decisional político autónomo e inescrutable del líder soberano no se aviene con un régimen democrático.

Otro elemento primordial es la temporalidad del estado de excepción. Las excepciones no son permanentes y si se volvieran permanentes el estado de excepción deja de ser el instrumento necesario para hacer frente a estas circunstancias. Efectivamente, una concepción republicana y democrática de estos exige que siempre se fijen límites temporales acotados y que cada prolongación sea revisada por órganos 
representativos y judiciales. No deben ser resorte exclusivo del ejecutivo la prórroga de este, ya que la posibilidad de prorrogar indefinidamente sin revisión alguna degenera la institución temporal en una institución permanente de facto.

Por último, el elemento primordial es la proporcionalidad del estado de excepción. Como no es efectivo cazar una mosca con una metralleta o un elefante con una pluma, los regímenes excepcionales deben satisfacer la proporcionalidad necesaria para el objetivo de sus fines. La restricción excesiva de libertades para circunstancias excepcionales de menor importancia o la restricción que resulta inocua al problema atacado son contrarias a la proporcionalidad debida y deben estar sujetas a la posibilidad antes mencionada de control parlamentario y judicial que puedan traducirse en responsabilidades políticas, penales y administrativas de las autoridades que han sobrepasado sus facultades.

\section{Bibliografía citada}

Aba Catoira, Ana (2011): "El Estado de Alarma en España”, Teoría y Realidad Constitucional, 0, 28: pp. 305-344

Ackerman, Bruce (2003): "The Emergency Constitution Essay", Yale Law Journal, 113, 5: pp. 1029-1091

Agamben, Giorgio (2011): La puissance de la pensée: essais et conférences (París, Payot Rivages).

Agamben, Giorgio y Gimeno Cuspinera, Antonio (2010): Estado de excepción: homo sacer II (Valencia, Pre-textos).

Ammirato, Scipione (1599): “Discorsi del signor Scipione Ammirato, sopra Cornelio Tácito", (Venecia, Filippo Giunti).

Anderson, Ben y Adey, Peter (2012): “Governing events and life: 'Emergency' in UK Civil Contingencies", Political Geography, 31, 1: pp. 24-33.

Ardant, Philippe y Mathieu, Bertrand (2018): Droit constitutionnel et institutions politiques: 2018-2019 (París, LGDJ).

Attali, Sophie (2008): "Le droit antisémite de Vichy: un droit politique d'exception". Disponible en: http://www.theses.fr./2008TOU10018 [Fecha de consulta: 4 de diciembre de 2020].

Barthélémy, Joseph (1915): "Notes de droit public sur le droit public en temps de guerre". Revue du droit public et de la science politique en France et à l'étranger, 1, pp.134-162.

Baudoui, Remi, El-Wakil, Alice y Gianni, Matteo (2016): "Etat d'exception, démocratie directe, exception démocratique : le cas suisse", En Jeu, 7: pp. 105-116

Beaud, Olivier y Bargues, Cécile (2018). L'état d'urgence: une étude constitutionnelle, historique et critique (París, LGDJ).

Benjamin, Walter (2008): Tesis sobre la historia y otros fragmentos (México DF, Ítaca).

Benjamin, Walter y Subirats, Eduardo (1998): Para una Crítica de la Violencia y Otros Ensayos. Iluminaciones $I V$ (Madrid, Taurus).

Blackstone, William (1979): Commentaries on the laws of England (Chicago, University of Chicago Press).

Blick, Andrew (2014): "Emergency powers and the withering of the Royal Prerogative", The International Journal of Human Rights, 18, 2: pp. 195-210.

Carré de Malberg, Raymond (2004): Contribution a la théorie générale de l'état spécialement d'aprés les données fourniers par le droit constitutionnel français (París, Dalloz). 
Chen, Albert (2009): "Emergency powers, constitutionalism and legal transplants: The East Asian experience", en Ramraj, Victor y Thiruvengadam, Arun (editores), Emergency Powers in Asia: Exploring the Limits of Legality (Cambridge, Cambridge University Press), pp. 56-88.

Cicerón, Marco Tulio (1980): La República (Madrid, Aguilar).

Cotter, Cornelius (1953): "Constitutionalizing Emergency Powers: The British Experience”, Stanford Law Review, 5, 3: pp. 382-417.

Delisle, Jacques (2009): "States of exception in an exceptional state: emergency powers law in China", en Ramraj, Victor y Thiruvengadam, Arun (editores), Emergency Powers in Asia: Exploring the Limits of Legality (Cambridge, Cambridge University Press), pp. 342-390.

Dicey, Albert (1982): Introduction to the study of the law of the constitution (Indianapolis, Liberty Fund).

Donoso Cortés, Juan (1946): Obras completas de don Juan Donoso Cortés, marqués de Valdegamas (Madrid, Biblioteca de Autores Cristianos).

Duverger, Maurice y Centre d'analyse comparative des systèmes politiques (1982): "Dictatures et légitimité”, (París, Presses universitaires de France)

Dyzenhaus, David (2009): “The Puzzle Of Martial Law”, University of Toronto Law Journal, 59, 1: pp. $1-64$.

Esteva Gallicchio, Eduardo (2002): "Los estados de excepción en Uruguay: hipótesis, aprobación y controles jurídicos o jurisdiccionales”, Ius et Praxis, 8, 1: pp. 147-169

Faggiani, Valentina (2012): "Los estados de excepción. Perspectivas desde el derecho constitucional europeo", Revista de derecho constitucional europeo, 17: pp. 181-232

Fenwick, Mark (2009) "Emergency powers and the limits of constitutionalism in Japan," in Ramraj, V. V. and Thiruvengadam, A. K. (eds) Emergency Powers in Asia: Exploring the Limits of Legality. Cambridge: Cambridge University Press, pp. 314-341

Fernández Segado, Francisco (1973): “El estado de excepción en el derecho constitucional español”. Disponible en: https://repositorio.uam.es/xmlui/handle/10486/10967 [Fecha de consulta: 4 de diciembre de 2020].

Fix-Zamudio, Héctor (2004): "Los estados de excepción y la defensa de la Constitución", Boletín mexicano de derecho comparado, 37, 111: pp. 801-860.

France, Assemblée nationale (1871-1942), Chambre des députés, Sénat (1879): Archives parlementaires de 1787 à 1860 (París: Librairie administrative de Paul Dupont).

François, Bastien (2017): Les mots clés du droit constitutionnel (París, Dalloz).

Furlong, Patrick, Indiana Historical Society y Indiana Association of Historians (1987): We the people: Indiana and the United States Constitution: lectures in observance of the Bicentennial of the Constitution (Indianapolis: Indiana Historical Society).

Gal, Sébastien Le (2017): “De 'l'état de siège réel' à 'l'état de siège fictif'”. Disponible en: https://hal.univgrenoble-alpes.fr/hal-01927519 [Fecha de consulta: 4 de diciembre de 2020].

García-Pelayo, Manuel (1984): Derecho constitucional (Madrid, Alianza).

Grosser, Alfred (1984): 10 leçons sur le nazisme (Bruxelles, Complexe).

Hauriou, Maurice (1909) notes sous l'arrêt CE, 7 août 1909, Winckel, S. 1909, III, R.D.P., p. 494-505

Hernández, Antonio María. Universidad Nacional Autónoma de México e Instituto de Investigaciones Jurídicas (2003): Las emergencias y el orden constitucional: la inconstitucionalidad del "Corralito" financiero y bancario (México, D.F., Culzoni Editores) 
Kantorowicz, Ernst (1989): Les deux corps du roi: essai sur la théologie politique du Moyeu Age (París, Gallimard).

Legal India (2020). “Can a pandemic ‘COVID19' be a ground to declare Health Emergency?”. Disponible en: https://www.indialegallive.com/top-news-of-the-day/news/can-pandemic-covid19-grounddeclare-health-emergency/ [Fecha de consulta: 4 de diciembre de 2020].

Linares Quintana, Segundo (1953): Tratado de la ciencia del derecho constitucional argentino y comparado: Teoría de la constitución (Buenos Aires, Alfa).

Loveman, Brian (1993) The Constitution of Tyranny: Regimes of Exception in Spanish America, (Pittsburgh, University of Pittsburg Press).

Machiavelli, Niccolò (2012): Discursos sobre la primera década de Tito Livio (Madrid, Alianza).

Manin, Bernard (2008): “The emergency paradigm and the new terrorism”. Disponible en: https://as.nyu. edu/content/dam/nyu-as/faculty/documents/emerg.pdf [Fecha de consulta].

Massot, Jean (2013): "Le Conseil d'État face aux circonstances exceptionnelles", Les Cahiers de la Justice, 2, 2: pp. 27-39.

Mayorga, Juan (1993): "El estado de excepción como milagro: de Donoso a Benjamin", ENDOXA, 1, 2: pp. 283-301.

Mbongo, Pascal (2017): L'état d'urgence: la prérogative et l'État de droit (Bayonne, Institut Universitaire Varenne).

Minerva Center for the Rule of Law under Extreme Conditions (2016a): "Emergency Laws and Regulations in Poland". Disponible en: https://minervaextremelaw.haifa.ac.il/images/Emergency_Laws_and_ Regulations_-in_Poland_19-_Jan2016.pdf [Fecha de consulta: 4 de diciembre de 2020].

--- (2016b): “Emergency Laws and Regulations in United States". Disponible en: https://minervaextremelaw. haifa.ac.il/images/Emergency_Laws_and_Regulations_-in_the_United_States-_19-_Jan2016.pdf [Fecha de consulta: 4 de diciembre de 2020].

Office Cabinet (2020): "Explanatory Notes to Civil Contingencies Act 2004”. Disponible en http://www. legislation.gov.uk/ukpga/2004/36/notes [Fecha de consulta : 4 de diciembre de 2020].

Real Academia Española: Diccionario de la lengua española, 23. ${ }^{\mathrm{a}}$ ed. Disponible en https://dle.rae.es [Fecha de consulta: 4 de diciembre de 2020].

Reinach, Theodore (2010): De L'Etat de Siege: Etude Historique Et Juridique (1885) (París, Kessinger Publishing).

Rousseau, Jean-Jacques (2009): El contrato social (Madrid, Edaf).

Saint-Bonnet, François (2001): L'état d'exception. Léviathan (París, Presses universitaires de France).

Salazar, Roberto (2018): “Véritable état d'exception», «violence pure» et «rédemption» Réflexion sur Benjamin et Agamben", Phantasia, 7: pp. 100-111.

Schmitt, Carl (1988): Théologie politique: 1922, 1969 (París, Gallimard).

--- (2015): La dictature (París, Seuil).

Trotter, Markus (1997): Der Ausnahmezustand im historischen und europäischen Rechtsvergleich (Heidelberg, Universität Heidelberg).

Valadés, Diego (1974): La dictadura constitucional en América Latina (México, UNAM).

Verdugo, Mario (1980): “Consideraciones sobre los regímenes de emergencia en el anteproyecto de Nueva Constitución”. X Jornadas de Derecho Público.

Willems, Pierre (2014). Le droit public romain ou Les institutions politiques de Rome depuis l'origine de la ville jusqu’à Justinien (París, Hachette Bnf). 


\section{Normas citadas:}

Decreto 100 (22/09/2005) Fija el texto refundido, coordinado y sistematizado de la Constitución Política de la República de Chile.

\section{Normas sugeridas:}

Constituição Da República Federativa do Brasil de 1988. Disponible en http://www.planalto.gov.br/ ccivil_03/constituicao/constituicao.htm [Fecha de consulta: 4 de diciembre de 2020].

Constitution of India. Disponible en http://legislative.gov.in/constitution-of-india

Constitution of Romania. Disponible en http://www.cdep.ro/pls/dic/site.page?den=act2_2\&par1=3 [Fecha de consulta: 4 de diciembre de 2020].

Constitution of the Republic of Bulgaria. Disponible en: https://www.parliament.bg/en/const [Fecha de consulta: 4 de diciembre de 2020].

Constitution of the Republic of Turkey. Disponible en https://www.anayasa.gov.tr/en/legislation/turkishconstiution/ [Fecha de consulta: 4 de diciembre de 2020].

"Constitute". Disponible en <https://www.constituteproject.org/>.

\section{Jurisprudencia citada}

Supreme court of the United States, Ex parte Milligan, 71 U.S. 4 Wall. 22 (1866) 